\title{
Institutional issues in planning for more uncertain futures
}

\author{
Greg $\operatorname{Marsden}^{1}$ (D) Noreen C. McDonald ${ }^{2}$
}

Published online: 1 August 2017

(C) The Author(s) 2017. This article is an open access publication

\begin{abstract}
Future travel demand has always been difficult to estimate. Recent trends of a slow down or stagnation in traffic growth combined with substantial demographic, economic, and technological shifts further complicate that task. This poses a significant planning challenge given that decision-making is often based on the benefits of infrastructure investments which accrue over periods as long as 60 years. In contrast to the changing ideas around what mobility in the future will look like and the types of demand it may need to service, the practice of forecasting future travel demand remains largely unchanged as do the decision-making processes which flow from this. Alternative approaches to thinking about futures such as scenario planning exist but have had more limited deployment in the transport sector. This paper explores the institutional issues surrounding the purpose, practice and barriers to changing the approaches of forecasting and decision-making through an exploration of the state of practice in the UK drawing on interviews with 23 practitioners. Drawing on Hall's work on policy change, the research finds that there is a strong policy paradigm built around the relationships between transport investment and traffic growth. This has strengthened since the recession with an increased focus on the relationship between transport and job creation. The forecasting approaches in use today are an important part of a complex decision-making apparatus reflective of specialized policy arenas like transport. Challenges in acknowledging, representing and communicating uncertainty are identified leaving a growing tension between planning visions and planning practice. We conclude by reflecting on events which may stimulate a broader reframing of how we plan for transport futures whilst embracing key uncertainties.
\end{abstract}

Keywords Forecasting · Uncertainty · Planning · Futures · Institutions

Greg Marsden

g.r.marsden@its.leeds.ac.uk

Institute for Transport Studies, University of Leeds, Leeds LS2 9JT, UK

2 Department of City and Regional Planning, University of North Carolina Chapel Hill, Chapel Hill, NC 27599-3140, USA 


\section{Introduction}

The period from the end of the second world war to the millennium saw the establishment and entrenchment of the automobile in every day life across many developed countries (Urry 2008). These patterns are repeating to varying degrees across the globe today with analysts suggesting the world vehicle fleet could grow from today's 1 billion to 2 billion by 2030 (Sperling and Gordon 2009) with passenger vehicle kilometres growing by between 117 and $233 \%$ over the same period (ITF 2015). Growth has been attributed to rising GDP and incomes, falling costs of ownership and increased provision of infrastructure (Dargay et al. 2007; ITF 2015).

The task of planning for transportation has evolved as traffic growth has continued from one which focussed largely on network supply (DoT 1989) to one which has accepted that supply cannot expand to meet demand and where the levels of growth need to be managed to limit congestion, air quality, safety, climate and social externalities (Buchanan 1964; Goodwin et al. 1991, Sadik-Khan and Solomonow, 2016). Nonetheless, the fundamental underlying logic of this period has been one where the growth in car use would come largely from a set of broadly consistent 'external drivers' which would lead to growth (ECMT 2003). The acceptance of the futility of seeking to fully accommodate this demand changed the policy question to one around how much demand would be catered for, how and where. The underlying pressure and logic of demand growth remained.

While there have been long-standing critiques of demand forecasting techniques (see Boyce and Williams (2016) for a comprehensive review of both the state of art and the critiques), recent events have highlighted more substantial divergence from previous trends which the established approaches did not anticipate and seem ill equipped to explain. After decades of steady increases in auto use, patterns reversed in the 2000s in many industrialized countries (Millard-Ball and Schipper 2010; Goodwin 2012b; Metz 2013). Aggregate driving on UK roads peaked in 2007, declined through 2010, and only began increasing in 2014 (DfT 2016a). On a per-capita basis, declines have been evident since the late 1990s/ early 2000s (DfT 2016b: p. 12). These changes have highlighted the sensitivity of the transport system to long-term societal shifts such as increasing labour market precarity and delays in household formation, partnering, and parenting; as well as shorter-term movements in oil prices and the macro economy (Blumenberg et al. 2016; Bastian et al. 2016; Ministry of Infrastructure and the Environment 2014; McDonald 2015; Vij et al. 2017).

Past experience tells us that a number of the factors which have traditionally defined the sector's understanding of future demand-such as employment, family structure, and income-have changed. There are also a range of new considerations which are present already, only to a small degree, but which could have profound impacts on how much and how we travel and for what purposes. Technological innovation has begun to alter the longstanding set of modal alternatives and attributes. Shared mobility services from car sharing to ride-hailing to person-to-person options provide on-demand mobility thereby challenging the traditional reliance on vehicle ownership and the resulting high fixed-cost structure of the transport market (Chase 2015). In the long-term, autonomous vehicles may provide the means to make vehicle ownership completely unnecessary or so inexpensive that a new type of auto domination perpetuates (Bansal and Kockelman 2017). The pervasive nature of mobile internet and internet enabled devices is also changing how we shop, network and co-ordinate activities (Lyons and Davidson 2016).

The assumption-that past relationships can adequately predict the future-is increasingly under challenge as we enter an age with unanticipated modal options, changing cost structures, and increasing economic divides. Even where uncertainty is 
accepted, the boundaries of such uncertainty are delimited quite narrowly. Walker et al. (2010: 918) suggest this typically encompasses "alternative, trend-based futures and/or different parameterizations of the system model" where "some estimate can be made of the probability of each of them". Essentially, the alternatives largely allow for variations in the underlying drivers of demand (GDP, oil price, population) but presume the underlying relationships remain the same. De Jong et al. (2007) also provide a useful international critique on the limited treatment of uncertainty in modelling.

While discussion of the future of mobility has been widespread, less attention has been paid to what this uncertain future means for the practice of transport infrastructure planning (Zmud et al. 2013; Ecola et al. 2015; Rohr et al. 2016). Alternative prescriptions such as dynamic and adaptive policy making (Walker et al. 2010; Marchau et al. 2010) and scenario planning (Schofer and Stopher 1979; Lyons and Davidson 2016; Banister and Hickman 2013) exist but they are not part of mainstream transportation planning practice. The answer to why there has been a lack of development and/or deployment of alternative approaches to forecasting may lie within the institutional settings of transportation planning. Here we take a broad interpretation of institutions to be the organisations, ways of working, rules and norms within which decisions are taken.

To understand the tensions in the current decision-making system and the potential, likelihood and process for changing how transport futures are used in planning we draw on Peter Hall's (1993) influential work on policy and paradigm change. Hall argues that, even where there is scientific debate about the need to change approaches to policy making, any change will be more political in nature depending on matters such as:

1. positional advantage within the institutional structure;

2. authority on matters of technical competence; and

3. instances of policy experimentation and policy failure.

Within his framework, Hall imbues policy arenas addressing highly technical issues as resistant to wider societal influence to change. This, he suggests, is because they have a body of specialised knowledge pertaining to them and there are firmly embedded operating procedures. The transport sector appears to have such characteristics and we review some of these further in "Background: decision-support and demand futures" section. Urry (2008: p. 344) suggests that the past century saw the "naturalisation of the car and its increasingly extensive lock-in with multiple institutions/organisations necessary for its expansion". This implies that the way the system is governed has become adapted to a norm of car growth that it is difficult to see beyond. Lyons and Davidson $(2016 ; 104)$ refer to this as "regime-compliant" planning. There is, of course, significant investment and knowledge built up around the existing ways of working and therefore a variety of costs associated with change (North 1990; Spinardi 2015). Work on transport planning in Sweden found "slow implementation of new notions, methods and scientific knowledge when practice is building mostly on experienced knowledge. It also opens up for unforeseen power relations and reinforces structures which do not necessarily promote change" (Antonson and Åkerskog 2015, p56).

Equally critical to a debate about changes to approaches to planning for transportation must be the visibility of a need to change. Here, Hall suggests that policy paradigms can be threatened by anomalies (as was the case in the economic policies of his initial case study). Here, the gap between observed transport trends and those that have been forecast previously would be the anomaly. He suggests that in response "ad-hoc attempts are generally made to stretch the terms of the paradigm to cover them, but this gradually undermines the intellectual coherence and precision of the existing paradigm" (p280) and this may, in- 
turn, lead to some experiments in policy adaptation. However, "if the paradigm is genuinely incapable of dealing with analogous developments, these experiments will result in policy failures that gradually undermine the authority of the paradigm and its advocates even further." (p280) It is argued in this paper that the debates surrounding 'peak car' and more uncertain transport futures reflect an on-going debate on paradigm coherence and that this forms an essential component of any institutional process of change to the practice of forecasting and planning for transport.

This article explores the extent to which different institutional factors constrain or facilitate the development of new ways of looking at the practice of national and regional long-range travel demand forecasting. The paper uses a case study of the United Kingdom where there exists a centralised and well documented set of tools and procedures through which strategic decision-making is conducted. It has also been the site of significant debate around changing mobility patterns and their implications for forecasting practice. Our research assesses three related research questions:

1. What is the purpose of forecasting and how have long-range forecasting tools and practices been adapted in response to uncertainty about future mobility patterns?

2. What are the institutional barriers to consideration of uncertainty in transportation infrastructure planning

3. What does the UK experience suggest for the ability for transport planning to adapt practices and techniques to address uncertainty in future travel behaviour?

The article introduces the review and interview method adopted for the study before setting out the approaches to decision-making and forecasting deployed in the UK. The interviews are used to reflect on each of the research questions in turn with the findings interpreted through reflection on the literature on institutional change which allows for the broader implications of the work to be considered. The paper concludes with a reflection on the potential for transport planning practices to adapt to more uncertain futures.

\section{Research approach}

To answer the research questions, we focus on the United Kingdom, particularly England, because the debates about paradigm coherence in the transport sector there have been prominent and transparent. Information on practice is gathered from published information and interviews with practitioners at regional and national levels. Conversations about UK forecasting practices have been well-captured in academic journals, websites, transport newsletters, and governmental reports from the Department for Transport, Transport Scotland, the Welsh Government Transport Ministry, as well as local and regional authorities. Interviews were conducted with current and former governmental staff and consultants involved with demand forecasting and strategic evaluation of transport schemes. Interviews with 23 individuals, 14 of whom gave consent to be quoted, were conducted in May and June 2016. Interview protocols were approved by the institutional review boards of the University of Leeds and the University of North Carolina at Chapel Hill.

At the time of initiating a nationwide set of road traffic forecasts, the Department for Transport (DfT) had responsibility for transport across the whole of the UK. Since devolution in 1998, Scotland and Wales have assumed many (although slightly different) powers for transport. The DfT therefore only has jurisdiction over English roads. Where 
this matters for forecasting practice or policy context we identify this although for many of the wider societal trends and technological changes, the underlying issues remain common. In such cases, we refer to the UK. Whilst each country will have its own structures and modelling approaches, the themes which we identify are not specific to the UK case study.

\section{Background: decision-support and demand futures}

All planning decisions require some form of prospective assessment of the future, whether this is what is perceived to be likely or desirable. The creation of demand futures, by whatever method, is therefore a part of the policy process and how it is done will be a function of the types of questions the process was aiming to answer. In exploring the institutional issues surrounding demand forecasting today it is necessary, therefore, to understand the institutional pathway through which the present day procedures emerged.

Since the 1960s the UK has operated some form of economic assessment of major transport schemes. The system has been highly centralised with allocations made by the UK government for motorways and the rail system as well as setting the rules and approvals process for local projects. Mackie and Worsley (2013) review the development of the appraisal process over time. They note that the scope of appraisal has widened and adapted to new policy priorities. In particular there is inclusion of a range of environmental factors, safety and more recently wider economic benefits such as agglomeration and job creation. Where possible, the UK seeks to monetise impacts but allows for assessments of overall value for money to be adjusted by consideration of the wider factors such as lost environmental amenity. All decisions were taken by the UK government on the basis of a relative assessment of the value for money of different investments. Benefit-cost ratios remain dominant in what is seen to be good value for money (for England see DfT 2015a) ${ }^{1}$ although a review of road projects in the late 1990s showed that, despite the importance of travel time savings to investment decisions, qualitative environmental factors did influence decisions (Nellthorp and Mackie 2000). Whilst some of the details of the approaches to assessing the benefits and costs of projects are different, the UK shares many similarities with other countries such as Sweden, the Netherlands, Germany, the US, New Zealand and Australia in the development of ex-ante scheme appraisal (Mackie and Worsley 2013; Quinet 2013; Romijn and Renes 2013). There appears though to be a stronger cross-project and cross-national comparative tradition resulting from the centralised approach to governance, particularly in England. All major strategies should have a Sustainability Assessment conducted and all projects have an Environmental Impact Assessment in line with European legislation. A full account of the evolution of transport and land-use planning can be found in Headicar (2009) if required.

In the UK major projects should be demonstrably consistent with national policy and there is, in turn, a need for local policy to be consistent with national policy. Here then it is important to recognise that forecasts are not separate from policy, nor solely an input to them, but intrinsically interwoven. As well as the forecasts being determined by the technical capabilities and know how of the time, they will also have been influenced by the political mood of the time which might steer, for example, what comprises 'low', 'high' and therefore 'central' forecasts. In 1989 for example, the forecasts came out alongside the

\footnotetext{
1 The Department for Transport classifies projects in the following bands of Value for Money: Poor (0.0-1.0), Low (1.0-1.5), Medium (1.5-2.0), High (2.0-4.0), Very High (4.0+) with only those scoring High or Very High seen to be strong candidates for investment. Value for Money is the Benefit:Cost Ratio adjusted by judgment for significant non quantifiable benefits or impacts.
} 
major road building programme announced by 'Roads for Prosperity' (DoT 1989). In 1997, an approach to managing rather than accommodating demand was adopted with a change in government (DETR 1998) reflected in a different approach to the application of the NTM (DETR 2000). Most recently (2009 and 2015) the forecasts have occurred on the back of the global financial downturn with the 2015 forecasts being produced with enough of a time lag to incorporate some of the understanding of the short-run effects of the downturn. There is an increased emphasis on infrastructure investment to stimulate growth and a strong positive association in policy between traffic growth and economic prosperity. The Treasury (rather than the DfT) has identified infrastructure investment as a major part of the economic stimulus package noting that "Infrastructure networks form the backbone of a modern economy and are a major determinant of growth and productivity... To remain globally competitive, the UK needs to address these failures [fragmentation and underinvestment] and develop an infrastructure capable of supporting a dynamic, modern economy" (HM Treasury 2011: 5, brackets added).

The DfT maintains several models to predict travel demand by mode for use in evaluation of national-level policy initiatives and strategic assessment of modal funding allocations. Traditionally, the forecasts and the demand implied from these models have been used as inputs to the business case for all major projects (those over $£ 10 \mathrm{~m}$ in value). Whilst each individual investment will be assessed through a more detailed bespoke model these tools and the national guidance on appraisal are an important guide for all decisions and for considering initial allocations across modes and areas. At a regional and local scale, the major cities in England are being given increased autonomy in determining how to spend capital allocations for major projects. However, the authorities are still required to make the case to national government for their funding settlements and so the extent to which previous national approaches to funding allocation remain important is an empirical question we explore.

\section{UK national road traffic forecasts and practice}

In this section, we present some of the key debates that have surrounded the National Transport Model for England and the production of forecasts of road traffic growth. The section begins by highlighting the identification of the anomaly between forecast and actual demand and the explanations for that. It provides brief descriptions of the National Transport Model and the adaptations that have been made in response to the critiques raised. The authors do not seek to take a position here of the elegance of the model nor the responses taken but to provide sufficient context for an international audience to understand this part of the institutional process of planning practice and the subsequent practitioner debate. We extensively reference the reports published to date and note that this is a debate which has a high degree of transparency.

Discrepancies between forecast and actual road traffic have been the anomaly motivating conversation about planning for long-range transport infrastructure. In 2012, Phil Goodwin, Professor of Transport Policy, showed forecast road travel was consistently higher than actual. For example, road traffic in 2005, prior to the global financial crisis, was less than the high and low forecasts from 1989 to 1997 (Fig. 1) (Goodwin 2012a). Presentation of the differences has been coupled with calls to review the National Transport Model (Buchan 2012; Metz 2014).

Road traffic forecasts (RTF) for the UK come from the National Transport Model (NTM), a four-step travel demand model augmented with sub-models for freight (Fig. 2). 


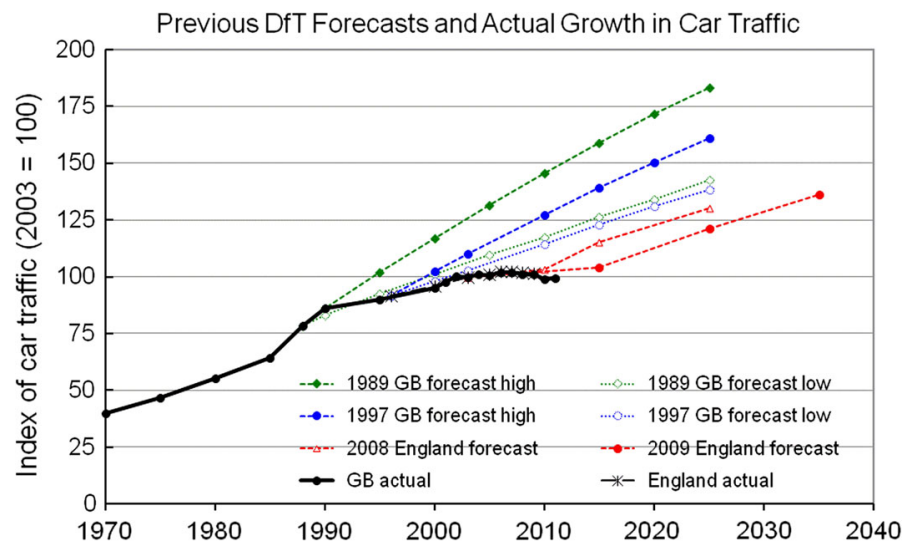

Fig. 1 Forecast and actual road traffic. Source reproduced with permission from Phil Goodwin

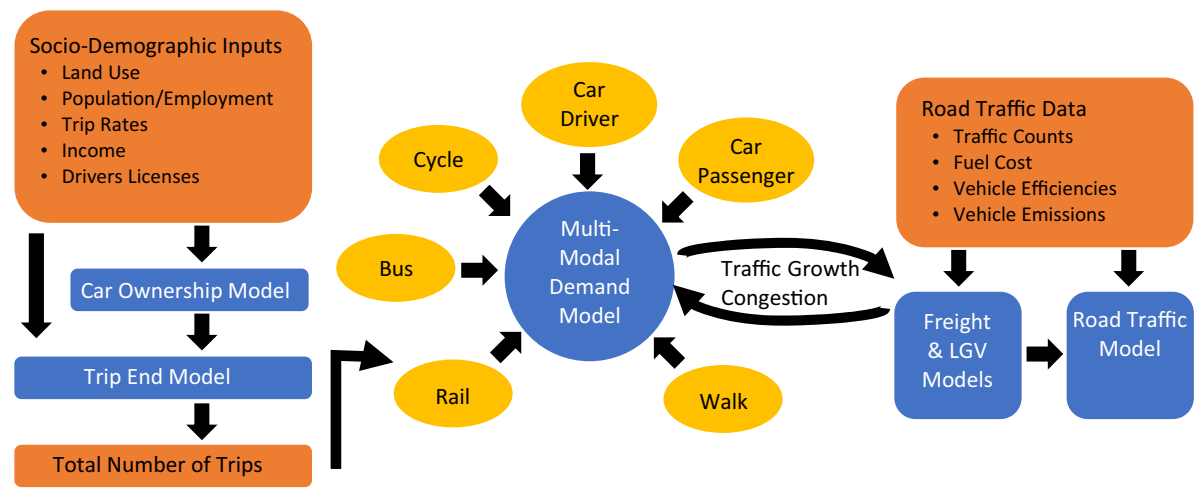

Fig. 2 Summary of national transport model structure. Note Adapted from DfT 2015b, p. 32

The NTM combines exogenous forecasts of future population and employment with models of travel behaviour to produce estimates of vehicle ownership, trips, trip distances and mode for each of 8 trip purposes across thousands of spatial zones (for brief description of model structure and approach see DfT 2015b; for in-depth description see DfT 2011). The translation of population and employment into trips is based on behavioural models calibrated from UK National Travel Survey data. Whilst the model produces multi-modal estimates of travel demand, DfT cautions against the reliability of nonroad forecasts (DfT 2015b: 30). Beyond road traffic forecasts, the NTM, specifically the National Trip End Model (NTEM), plays a role in local and regional transport planning. The Department provides regions with tools to develop scenarios that adjust future employment and population growth whilst adhering to control totals on study area trip making developed from the NTEM (DfT 2017a). A single core scenario is used for all projects which is consistent with NTEM and high and low growth variants are tested consistent with national guidance. ${ }^{2}$ There remains, therefore, significant national oversight and influence on local and regional processes.

\footnotetext{
2 https://www.gov.uk/government/publications/webtag-tag-unit-m4-forecasting-and-uncertainty-November-2014.
} 
The dialogue on the causes and implications of observed differences in road travel can be viewed as an extended conversation on the paradigm coherence of methods for allocating transport infrastructure resources. For example, some explanations for differences between forecast and observed demand do not challenge the current transport planning paradigm. London road conditions in the NTM did not reflect capacity reductions due to bus and bike lane improvements; the most recent 2015 forecasts include more accurate road capacity assumptions (DfT 2015b, p. 15). Macroeconomic shocks associated with the GFC also caused difficulties to predict travel decreases due to declines in industrial output and employment.

Other explanations for the gap between forecast and actual road traffic challenge current assumptions about connections between economic and traffic growth and underlie debates about how behavioural assumptions should influence policy decisions. NTS data have shown sustained decreases in trip making and a declining connection between income and auto ownership over the past 20 years (DfT 2015c). DfT has recently updated the trip generation and auto ownership models with new rates reflective of recent (2011) behaviour; the impact has been a decrease of $19-24 \%$ in the volume of trips predicted annually in the UK from 2011 to 2041 compared to the previous model (DfT 2017a, p. 59).

Observing the structure and stated purpose of the model raises some issues which we return to through the interviews. First, there remains a clear distinction at a national level between forecasting for road, rail and local transport. Second, the national transport model is intended to provide some form of consistency of approach to understanding demand at a regional and local level. These are historical institutional features rather than necessarily being technically optimal. Finally, the model structure is based on the assumption of a set of relationships between income, driving license holding and car ownership which have been well understood as car ownership boomed but which we highlighted in "Introduction" section may now in a period of significant flux.

\section{Analysis}

The analysis follows three themes which emerge from the interviews, organised to help answer the research questions set out in "Introduction" section.

\section{Consideration of uncertainty and changing behaviour}

The public dialogue about the accuracy of the DfT's national road traffic forecasts created a pressure to re-evaluate the underlying assumptions to ensure the continued credibility of modelled results. Such challenges could be quite problematic for a government because the forecasts and associated trip models underlie funding allocations and business cases for all projects.

DfT has traditionally considered uncertainty around macroeconomic conditions by producing three sets of road traffic forecasts: core (or central), low growth (high gas prices/ low GDP), and high growth (low petrol prices/high GDP). To assess the impacts of behavioural change, the 2015 RTF introduces two additional scenarios. The first uses new (lower) trip generation rates calibrated to more recent NTS data (p. 35). The next models road traffic assuming there is no relationship between income and car travel. Resulting forecasts predict sharply different growth trajectories. For example, using lower trip rates 
decreases estimates of traffic in 2040 by approximately 65 billion miles or $18 \%$ from the central forecast (DfT 2015b, p. 41).

The overall fan of traffic levels between the lowest and highest forecast is now some 100 billion vehicle kilometres per year by 2040 , or $44 \%$ of the 2010 levels from which the growth was estimated. Although this approach only deals with a small part of the potential set of uncertainties (Walker et al.'s (2010) definition of Level 2 uncertainty) it is still quite substantial in its potential implications for policy. How might decision-makers respond to such uncertainty?

Interviewees gave inconsistent reports of the appetite of elected officials for information on the uncertainty of future forecasts. A minority of interviewees felt elected officials and agency leaders wanted to understand the full range of possible outcomes in order to select the best funding strategies. These were often planners working at the national level. At the regional level, opinions were more split. Some felt there was strong interest: "politicians have generally embraced that [uncertainty] a lot, really with open arms, because politicians almost by definition are suspicious of black box solutions." Others were more sceptical about the interest in multiple scenarios or forecasts, partly because of the difficulties in presenting what that actually means:

I mean, I'm sure any [title redacted, elected official] will say is, "I don't want 53 forecasts, give me a central forecast"

"Oh yeah, 21,472 vehicles a day..." whereas in fact it could be anything from 12 up to 50 but if you presented that information to the public or to politicians it would lose its credibility wouldn't it? "How can you have a forecast between 12,000 and 50,000 ?" they'd say.

The updates of the NTM show the Department's concern with and responsiveness to critiques of the model. Addressing the critiques is critical to maintaining credibility of the transportation planning process, but also introduces potential discontinuities with previous assumed demand. However, whilst that potential exists, there has been no shift in approach to the treatment of future demand dealing with this much wider fan of uncertainty. The approach adopted is consistent with Hall's suggestion of development within the existing paradigm.

Representatives from most regional and local agencies reported awareness of internal discussions about technological, demographic, and behavioural changes that might lead to shifting travel demand patterns. As several regional planners stated:

It [changing travel patterns]'s something that we do debate. Certainly looking at the data we've got, there does seem to be a suggestion that the trips-per-capita by car overall fits in with this "peak car" theory, if you like.

We're currently developing our 2040 transport strategy and that strategy is mainly central about the innovation and technology and how transport planning can consider... and how much impact that would have on our policies and our strategies. So that's very much central to the discussion at this moment happening in [redacted] and politicians are very keen for us to understand and bring that kind of activity into our planning.

However, acknowledgement of the potential import of these issues was also not coupled with changes in processes. Planners expressed concerns that the trends were difficult to incorporate into current planning tools for scheme appraisal because the causes are not well understood. For example: 
We have to ... consider the policy implications [of changing mobility]. And then to what extent do we reflect that in our modelling? ... We're not prepared for that in our forecasting.

There are things that get murmured around like automated cars and deliveries, home deliveries, how is that going to impact; but I don't believe we've got anywhere near the answers. It's hard enough predicting normal stuff let alone how home deliveries are going to affect your shopping patterns.

I mean you might look at things like household size, household compositions; those are tractable things that people have been doing for decades. But real change, either structural economic change or socioeconomic change, attitudes, preferences, behaviour, those are things that are just difficult to deal with in long-term forecasting processes.

we need to put our own scenario together and we don't necessarily want to understand or we haven't got the time to unpick different car ownership or behavioural patterns, ... so we jump straight to.

Whilst there was little attention on how forecasting practices at the regional level might accommodate different emerging mobility futures, there was a focus on the operational uncertainty caused by current manifestations of changing mobility patterns and modal options. For example, a regional agency identified tracking and understanding changing bus usage patterns, particularly among the elderly, as an important component of their work. This was because seniors are eligible for concessionary fares-the costs of which must be covered by local and regional authorities - and the budgetary impacts could be substantial. Similarly another agency noted a desire to better understand use of ride-hailing services such as Uber because of the possibilities of needing to oversee the service in the future. As the planner summarized:

we do spend quite a lot of time analysing and trying to understand them [ride-hailing services], but not necessarily then trying to forecast and predict.

This could be seen to be early evidence of the divergence between recent trends and the potentially disruptive impacts of new technologies in the present day which is not yet a feature of future planning despite being prominent in long-term industrial and technology strategies.

\section{Contemporary policy focus}

It seems therefore that greater uncertainty in future demand is accepted but not incorporated. It is not that these changes do not matter to transport planners, they just do not matter enough now to address any shortcomings which the existing approaches might have. An uncertainty about how to address these new trends is one reason posited above. However, as we explore in this section, progress is being made on addressing uncertainties, just different ones and ones which are more politically salient. In particular here, the changing economic narrative since the global financial crisis on the purpose of infrastructure investment and its role in creating, sustaining or 'unlocking' jobs. As aptly put by a planner: 
so it was all about the economy, economy, economy, economy. Did I say it was about the economy? It was about the economy. And before you think about anything else it's about the economy.

One of the challenges of imagining different demand futures in the current environment is that the construction of new infrastructure is seen as an essential part of future productivity growth. Futures therefore which have more limited demand growth or even, as Lyons and Davidson (2016) posit for New Zealand, reductions in travel are inconsistent with the embodied belief system of what transport investments are for and the relationship between growth in transport and growth in the economy (see also "Background: decisionsupport and demand futures" section).

Recent devolution in decision-making authority from central government to local and regional authorities has given sub-national entities the role of identifying and prioritizing investments. These changes have been spurred by efforts to promote economic development and in some cases are explicitly linked to the goal of growing the economy. The conditions set for devolving funding have focused local transport planning agencies on evaluating not just the transport benefits of proposed schemes (generally travel time savings) but wider impacts around employment. Standard tools and processes have not been previously been in place to guide the definition and measurement of measures of economic benefit such as gross value added. This has led to innovation, as regions have developed business cases that focus on job creation and economic development impacts, as well as the traditional metrics around travel time savings and the related benefit-cost ratio. This switch has required agencies to continue doing traditional cost-benefit analyses as prescribed by DfT in order to ensure value for money, but it has also necessitated that many of them develop a set of strategic models (often transportation-land use interaction models) that are used to estimate employment and wider economic benefits that are integrated into a broader strategic case. Several interviewees detailed how devolution has affected their use of tools, planning processes, and sources of funding:

In the context of devolution and certainly for combined authorities, transport has been elevated into wider economic strategies so now there are these strategic economic plans which tell a much broader story, and in a way sort of local bodies saying what they think the future is going to look like.

as devolution develops you have lots of different masters and possible sources of funding so it's no longer me and the Department for Transport. It's lots of people it was very much a case of let's look at the full benefits of any schemes that are going on rather than just the narrow central government defined view of things.

Transportation agencies can be seen to act as budget maximising entities (Niskanen 1968) with a desire to extract funding from national and regional/local competitions. This tradition is particularly strong in the UK given the strong control over local public spending exerted by central government. The current framing around which funding is allocated has largely been driven by an overarching economic narrative and the need to demonstrate agglomeration benefits, job creation potential and the relationship between investments and uplift in economic Gross Value Added (DfT 2014). The effort required to develop these processes, craft an economic business case for proposed schemes, and complete standard DfT-compliant analyses of BCR is large. Most regions did not then have additional time or staff available to consider the impacts of long-term changes in transport 
demand or uncertainty in these forecasts. Nor is such uncertainty a feature in the current funding 'rules of the game' as the local stakeholder below set out:

so if I'm a local authority and I'm trying to get some money from government or even tell an internal story to my politicians to get some money for transport it's great if I can take the Department for Transport's road traffic forecast. I say "Well, in 30 years' time [redacted] will have ground to a halt because I've got these road traffic forecasts; I won't question them now. They tell me this is just shooting up so I need more transport investment." So that's quite a handy thing; it's handy not to have to question that.

This approach is consistent with Lyons and Davidson's $(2010 ; 110)$ assessment of a "practical" worldview where the outlook for the future "aligns best with immediate interests and imperatives".

\section{Institutional arrangements}

Current tools and processes reflect the global intellectual history of the field and the particularities of UK transport planning as set out in "Background: decision-support and demand futures" section. DfT, as the primary funder of transport infrastructure, developed a set of practices and protocols that allowed efficient allocation of funds. A standard set of national models and approaches was critical so that decisions were not influenced by overly optimistic assumptions by certain regions.

the Department of Transport's job, it had a pot of money that was fixed, and it was capital rationing, and therefore there might be some uncertainty with that forecast, but ... it's a relative exercise.

What the government want is to be able to compare every project on an equal footing and then allocate that in the hope that this is the most efficient allocation possible, and so the most important thing is to have equal standards for everybody and an agreed common view of the world of the future. So that's where this has come from.

Yet these processes and tools that allow for fair comparison can make consideration of uncertainty difficult. First, behavioural relationships are captured in hundreds of model parameters that represent the relationship between socio-economic characteristics and travel. This creates issues around which parameters should be changed and how they should be changed. DfT's recent efforts for the 2015 RTF show how these parameters can be adjusted to assess particular scenarios. However, the approach was never really developed for good cross-modal planning nor for more detailed local or regional planning and issues regarding divergence remains.

What we see is the critical role that central government guidance plays in the definition of and consideration of uncertainty in UK transport planning. Many regions won't consider changing practice until the tools are available from DfT. This reinforces one of the findings from studies of multi-level governance in the UK transport sector (Marsden et al. 2014) which suggested very limited incentive for lower tiers of government to be divergent from higher tiers due to their resource dependency. However, this seems to go beyond just resources but reflects a strong 'institutionalization of ideas' across the sector. Radaelli $(1995 ; 178)$ suggests that "institutions give stability to shared causal beliefs, they set up structures of meaning, they create networks of actors, they constrain the perception of interests and socio-economic change". Here it seems difficult for regional actors to have 
future demand forecasts that are not based on the same premise as those of national government. As we note above whilst it would be difficult for them to do so, there also appears little incentive to depart from future assumptions which support infrastructure investment ambitions.

The historical reasons for the current approach to forecasting (central funding allocation) seem to be constraining, to some extent, the future directions that can be considered. For example, visions of future transport that have high levels of mobility as a service and autonomous transportation will need to be capable of re-imagining how we travel, when and for what purposes. However, the demand futures which road and regional transport planners are working to are all premised around relationships based on, for example, a car ownership model (Fig. 2).

The strong siloed modal traditions within transport also seem set to play a role. Rail futures are equally anchored in their own modal history and policy sub-system with little interest being expressed in understanding what these future changes might mean for rail markets. Contrasting the amount of effort spent on updating road versus rail tools one rail observer noted "I don't think the rail sector is very good at predicting and responding to changes in travel behaviours. I think actually the rail sector is incredibly parochial, and they just assume it will be okay". This echoes Low and Astle's (2009) finding that road forecasting tends to have a more developed science base than that for public transport. A second interviewee noted "the long distance market is in danger of getting absolutely stuffed because autonomous cars and the price of the electric travel [lower marginal mileage costs by car] could significantly reduce the cost of traveling by road compared to rail" (brackets added). Comparatively little as been done to address the on-going distinction between road and rail network forecasting.

The current system displays many characteristics of a socio-technical system in some form of lock-in with a large and invested set of skills which imbues confidence in the existing set of practices (Kay 2006; Antonson and Åkerskog 2015 and Spinardi 2015).

\section{Discussion}

Reflecting back on Hall's understanding of processes of policy change we can see two countervailing forces in the debate around transport futures. The first is the challenge to existing processes based around the increasingly accepted anomalies between current trends and past modelled performance. We acknowledge the continued efforts of the DfT to ensure that their model is well calibrated to contemporary data and to respond to challenges raised. The anomaly arguments have not yet however been sufficiently large to have undermined the technical tools deployed across the sector. We suggest though that recent updates to underlying trips rates, which removed nearly a quarter of expected trips, go well beyond previously accepted policy wisdom about what levels of behavioural adaptation travellers could achieve (e.g. CCC 2016). These effects are yet to ripple through the planning process and this debate will grow. Coupled with this is evidence that local transport bodies are already seeking to understand the impacts of new forms of mobility on their networks and on their role as transport agencies yet these are not part of a set of assumptions which define future demand. 'Business as Usual' or 'do-minimum' ignores elements of the mobility system which are here today and which, elsewhere, form part of government imaginings of transport futures. For example, whilst the government has an aspiration that all vehicles will be electric vehicles by 2050 there are no assumptions about 
how this might shape demand in the forecasts. The same goes for mobility as a service and increased automation. This is a further anomaly.

The second force though is the wider political agenda which is reinforcing current practice and pushing its extension into ever more complex questions around job creation and agglomeration benefits. This could demonstrate confirmation bias where the strategy and investment narrative is around investment in infrastructure and so future demand growth forecasts face limited challenge. There is a very strong political and institutional axis which supports the continuation of an adapted business as usual approach.

Whether this tension needs to be resolved will depend on the readers' own position on the strength of the anomaly arguments and the capability of the existing paradigm to continue to provide sufficiently robust answers given the greater range of accepted uncertainty identified. Derbyshire $(2016 ; 48)$ neatly sums up the dilemma facing transportation planning "Overly-focusing on how past developments have led to the present renders it difficult to think about how the future may develop in unexpected ways. However, conversely, focusing too much on the latter (potentially unexpected developments) results in our considerations of the future appearing disconnected from the present and past from which it emerges". We suggest some ways in which the challenge and debate will unfold.

First, the fundamental distinctions between forecasting on the basis of past projections and more vision or scenario based approaches to planning are not addressed through incremental development of existing tools. As Watson (2012) points out, the changes to how and why we move around will be an on-going process and so we will always see traces of travel which are diminishing as well as new ways of doing things which are growing. Whilst we are at the foothills of larger changes, new ways of doing things which may better reflect future demand will inevitably be small in our data sets. Recalibration of existing tools brings no guarantee of adequately capturing the impact such changes will have in the longer run as it can only capture what impact they have had to date. Such an approach would also fail to capture more substantial changes if changes reach a critical mass or 'tipping point' as suggested by Urry (2004). The scale of changes identified in recalibrations and their cumulative impact over time gives an indication of the importance of the anomalies.

We have not, through this study, developed a preferred solution or clear optimal way of understanding demand in the future although we have highlighted several options developed elsewhere (Walker et al. 2010; Marchau et al. 2010; Banister and Hickman 2013; Lyons and Davidson 2016;). We suggest that a bigger and more immediate challenge to changing practice is a fundamental reframing of the transportation debate. Since the global financial crisis transportation investment has been reinforced as a central pillar of growth stimulation and a symbol of efficiency and modernity. The narrative is that good transport stimulates jobs and therefore more mobility, therefore more mobility is hard to challenge ('or don't you want those jobs?'). There is currently little or no space to reframe the debate about the changing relationship between the economy and travel, little incentive to do so (as that is where what limited public spending is available to promote) nor the technical capacity to do so (given the focus on developing new methods for justifying investments in terms of gross value added and jobs). Despite the acceptance that 'predict and provide' does not work, the assumed relationships between transport and the economy which dominate policy thinking today are not dissimilar from those which were in place as automobility took off and so we seem unable to shake ourselves from Lyons and Davidson's categorisation of a regime compliant pathway. To challenge this requires identifying strong evidence of which sites and contexts do not illustrate these traditional relationships 
and to understand the different role that transport plays in creating these attractive and highly productive cities and areas. This reframing could unlock different needs from the supporting analytical system.

Linked to this is the potential for greater polycentric governance (Ostrom 2010) with the devolution of transportation powers and budgets to regional and local transport planning bodies in England which may yet provide opportunities to think differently. London for example suggests that it has a different set of demand trends unfolding to the rest of the UK (TfL 2014). Also, places where innovations are being more strongly promoted and adopted could result in a bottom up identification for a different set of future investment needs and therefore a different approach to thinking about the future. However, for the reasons set out above, this seems some way off in England right now as the need for consistency with central government processes remains strong.

It is also possible, although probably over a longer time period and likely less desirable, that the anomaly debate will become more definitive in nature. There are statutory procedures such as planning appeals which could be used by groups objecting to infrastructure schemes to cast doubt on the demand forecasts currently deployed. Indeed, even under the existing paradigm planning inspectors have identified risks from "structural changes in the demand for transport" (Whitehead 2015: 337) as a contributory factor to declining a major public transport scheme in the northern city of Leeds. If the anticipated trends in shared smart mobility and automation continue to develop then the current forecasting approach and model structure may struggle to withstand these different forms of scrutiny.

Greater thought also, therefore, needs to be given to the timing of any change in approach. At any point in time there is several billion pounds worth of infrastructure investment both under active construction and development in the pipeline. The practical implications of radically changing demand assumptions and the risks of legal challenges to such schemes seem non-trivial (even where the case for investment might remain sound). This is where greater thought about tools which allow for divergent pathways in their assessment may be helpful as some schemes can be justified under a number of futures (e.g. Foxon et al. 2013).

This paper set out to explore the challenges in current practices of planning for transportation. Whilst at the heart of the debate is an inevitable on-going technical and scientific puzzling over whether we are doing the right thing and whether our tools are adequate for the job, the research has uncovered the wider importance of the institutional context and the political narratives at play that shape the evidence that is needed and the histories and focus of the dominant technical practices. Although many of the technical challenges raised here will matter in a range of places, the institutional structures and traditions will be distinct and so we might anticipate different responses over time in different places. Perhaps it will be through experimentation and learning that the potential for a transition in the practice of transportation planning will be seen to be feasible. It may be a necessary transition to accompany that foreseen for the future of mobility.

Acknowledgements Funding for this research came from the DEMAND Centre funded by a grant from the Research Councils UK (EP/K011723/1) and the US-UK Fulbright Commission. The authors would like to thank the participants for their time, Dr Louise Reardon for her insights in reviewing an early draft and the three anonymous reviewers for their comments.

\section{Compliance with ethical standards}

Conflict of interest On behalf of both authors, the corresponding author states that there is no conflict of interest. 
Open Access This article is distributed under the terms of the Creative Commons Attribution 4.0 International License (http://creativecommons.org/licenses/by/4.0/), which permits unrestricted use, distribution, and reproduction in any medium, provided you give appropriate credit to the original author(s) and the source, provide a link to the Creative Commons license, and indicate if changes were made.

\section{References}

Antonson, H., Åkerskog, A.: This is what we did last time”. Uncertainty over landscape analysis and its procurement in the Swedish road planning process. Land Use Policy 42, 48-57 (2015)

Banister, D., Hickman, R.: Transport futures: thinking the unthinkable. Transp. Policy 29, 283-293 (2013)

Bansal, P., Kockelman, K.M.: Forecasting Americans' long-term adoption of connected and autonomous vehicle technologies. Forthcom. Transp. Res. Part A 95, 49-63 (2017)

Bastian, A., Börjesson, M., Eliasson, J.: Explaining "peak car” with economic variables. Transp. Res. Part A 88, 236-250 (2016)

Blumenberg, E., Ralph, K., Smart, M., Taylor, B.D.: Who knows about kids these days? Analyzing the determinants of youth and adult mobility in the US between 1990 and 2009. Transp. Res. Part A 93, 39-54 (2016)

Boyce, D., Williams, H.: Forecasting Urban Travel: Past, Present and Future. Edward Elgar, Cheltenham (2016)

Buchan, K.: Review national transport model. https://www.transportxtra.com/publications/local-transporttoday/news/30218/-review-national-transport-model(2012). Accessed 29 July 2017

Buchanan, C.: Traffic in Towns. Report to the Ministry of Transport, Penguin (1964)

CCC: Meeting Carbon Budgets-2016 Progress Report to Parliament, Committee on Climate Change, London. https://www.theccc.org.uk/publication/meeting-carbon-budgets-2016-progress-report-toparliament/ (2016). Accessed 19 May 2017

Chase, R.: Public Affairs. Peers Inc., Washington (2015)

Dargay, J., Gately, D., Sommer, M.: Vehicle ownership and income growth, worldwide:1960-2030. Energy J. 28(4), 143-170 (2007)

De Jong, G., Daly, A., Pieters, M., Miller, S., Plasmeijer, R., Hofman, F.: Uncertainty in traffic forecasts: literature review and new results for the Netherlands. Transportation 34, 375-395 (2007)

Derbyshire, J.: The implications, challenges and benefits of a complexity-orientated Futures Studies. Futures 77, 45-55 (2016)

DETR: A New Deal for Transport: Better for Everyone. Department of Environment, Transport and the Regions, Cm 3950, London (1998)

DETR: Transport 2010: The 10 Year Plan for Transport. Department of Environment, Transport and the Regions, London (2000)

DfT: The National Transport Model Web Archive. http://webarchive.nationalarchives.gov.uk/ 20110202223628/http://www.dft.gov.uk/pgr/economics/ntm/ (2011). Accessed 28 April 2017

DfT: TAG UNIT A2.1 wider impacts. Department for Transport, London. https://www.gov.uk/transportanalysis-guidance-webtag (2014)

DfT: Road Investment Strategy: for the 2015/16 to 2019/20 Road Period. London. https://www.gov.uk/ government/uploads/system/uploads/attachment_data/file/408514/ris-for-2015-16-road-period-webversion.pdf (2015a). Accessed 01 Nov 2016

DfT: Road Traffic Forecasts 2015. London. https:/www.gov.uk/government/uploads/system/uploads/ attachment_data/file/411471/road-traffic-forecasts-2015.pdf (2015b). Accessed 01 Nov 2016

DfT: Understanding the drivers of road travel: current trends in and factors behind road use. London. https://www. gov.uk/government/uploads/system/uploads/attachment_data/file/395722/understanding-the-drivers-road_ travel.pdf (2015c). Accessed 01 Nov 2016

DfT: National Road Traffic Survey: table TRA0102: motor vehicle travel (miles) by road class in Great Britain, annual from 1993. London. https://www.gov.uk/government/statistical-data-sets/tra01-trafficby-road-class-and-region-miles (2016a). Accessed 01 Nov 2016

DfT: Road use statistics Great Britain 2016. London. https:/www.gov.uk/government/uploads/system/ uploads/attachment_data/file/514912/road-use-statistics.pdf (2016b). Accessed 01 Nov 2016

DfT: NTEM Planning Data Version 7.2: Guidance Note. London. https://data.gov.uk/dataset/national-tripend-model-ntem (2017a). Accessed 28 April 2017

DoT: Roads for Prosperity, Cm 693. Department of Transport, London (1989)

ECMT: Managing the fundamental drivers of transport demand, European conference of ministers on transport. https://www.itf-oecd.org/managing-fundamental-drivers-transport-demand (2003) 
Ecola, L., Zmud, J., Gu, K., Phleps, P., Feige, I.: The Future of Mobility: Scenarios for china in 2030. DC: RAND Corporation, Washington. http://www.rand.org/pubs/research_reports/RR991.html (2015)

Foxon, T.J., Pearson, P.J., Araposthathis, S., Carlsson-Hyslop, A., Thornton, J.: Branching points for transition pathways: assessing responses of actors to challenges on pathways to a low carbon future. Energy Policy 52, 146-158 (2013)

Goodwin, P., Hallett, S., Kenny, F., Stokes, G.: Transport: The New Realism. Transport Studies Unit, Oxford University, Oxford, Working Paper 624 (1991)

Goodwin, P.: Due diligence, traffic forecasts and pensions. Local transport today, 13 Apr 2012. http://www. bettertransport.org.uk/campaigns/roads-to-nowhere/ltt-130412 (2012a). Accessed 01 Nov 2016

Goodwin, P.: "Peak Travel, Peak Car and the Future of Mobility: Evidence, Unresolved Issues, and Policy Implications, and a Research Agenda", ITF Discussion Paper No. 2012-13, www.internationaltran sportforum.org/jtrc/DiscussionPapers/DP201213.pdf (2012b)

Hall, P.A.: Policy paradigms, social learning and the state: the case of economic policy making in Britain. Comp. Polit. 25(3), 275-296 (1993)

Headicar, P.: Transport Policy and Planning in Great Britain. Routledge, Oxford (2009)

HM Treasury: The National Infrastructure Plan 2011. London. http://webarchive.nationalarchives.gov.uk/ 20130129110402/http://cdn.hm-treasury.gov.uk/national_infrastructure_plan291111.pdf (2011). Accessed 01 Nov 2016

ITF: ITF Transport Outlook, International Transport Forum, OECD, http://www.oecd.org/environment/itftransport-outlook-2015-9789282107782-en.htm (2015). Accessed 01 Nov 2016

Kay, A.: A critique of the use of path dependency in policy studies. Public Adm. 83(3), 553-571 (2006)

Low, Astle, : Path dependence in urban transport: an institutional analysis of urban passenger transport in Melbourne, Australia, 1956-2006. Transp. Policy 16(2), 47-58 (2009)

Lyons, G., Davidson, C.: Guidance for transport planning and policymaking in the face of an uncertain future. Transp. Res. Part A 88, 104-116 (2016)

Mackie, P., Worsley, T.: International Comparisons of Transport Appraisal Practice: Overview Report, Institute for Transport Studies, University of Leeds (2013)

Marchau, V.A.W.J., Walker, W.E., van Wee, G.P.: Dynamic adaptive transport policies for handling deep uncertainty. Technol. Forecast. Soc. Change 77, 940-950 (2010)

Marsden, G., Ferreira, A., Bache, I., Flinders, M., Bartle, I.: Muddling through with climate change targets: a multi-level governance perspective on the transport sector. Clim. Policy 14, 617-636 (2014)

McDonald, N.C.: Are millennials really the 'go-nowhere' generation? J. Am. Plan. Assoc. 81(2), 90-103 (2015)

Metz, D.: Peak car and beyond: the fourth era of travel. Transp. Rev. 33(3), 255-270 (2013)

Metz, D.: NNNPS Statement. http://peakcar.org/wp-content/uploads/2014/02/metz-nnnps-response-26-2-14. docx (2014). Accessed 01 Nov 2016

Millard-Ball, A., Schipper, L.: Are we reaching peak travel? Trends in passenger transport in eight industrialized countries. Transp. Rev. 31(3), 357-378 (2010)

Ministry of Infrastructure and the Environment.: Not car-less, but car-later. The Hague: Ministry of Infrastructure and the Environment. https:/english.kimnet.nl/publications/reports/2014/06/10/notcarless-but-car-later (2014). Accessed 13 Sept 2016

Nellthorp, J., Mackie, P.J.: The UK Roads Review—a hedonic model of decision making. Transp. Policy 7, 127-138 (2000)

Niskanen, W.A.: The peculiar economics of bureaucracy. Am. Econ. Rev. 58(2), 293-305 (1968)

North, D.: Institutions, Institutional Change and Economic Performance. Cambridge University Press, Cambridge (1990)

Ostrom, E.: Polycentric systems for coping with collective action and global environmental change. Glob. Environ. Change 20(4), 550-557 (2010)

Quinet, E.: L'évaluation socio-économique des investissements publics, rapport du Commissariat Général à la Stratégie et à la Prospective, La Documentation Française, Paris. http://blog.en.strategie.gouv.fr/wpcontent/uploads/2014/04/CGSPCALCUL_SOCIOECONOMIQUE_english.pdf (2013). Accessed 29 July 2017

Radaelli, C.M.: The role of knowledge in the policy process. J. Eur. Public Policy 2(2), 159-183 (1995)

Rohr, C., Ecola, L., Zmud, J., Dunkerley, F., Black, J., Baker, E.: Travel in Britain in 2035. UK: RAND Corporation, Cambridge. http://www.rand.org/content/dam/rand/pubs/research_reports/RR1300/ RR1377/RAND_RR1377.pdf (2016)

Romijn, G., Renes, G.: General guidance for cost benefit analysis, Report for CPB Netherlands Bureau for Economic Policy Analysis PBL Netherlands Environmental Assessment Agency. http://www.pbl.nl/ sites/default/files/cms/publicaties/pbl-cpb-2015-general-guidance-for-cost-benefit-analysis_01512.pdf (2013). Accessed 29 July 2017 
Sadik-Khan, J., Solomonov, S.: Street Fight. Viking, New York (2016)

Schofer, J.L., Stopher, P.R.: Specifications for a new long-range urban transportation planning process. Transportation 8, 199-218 (1979)

Sperling, D., Gordon, D.: Two Billion Cars: Driving Toward Sustainability. Oxford University Press, Oxford (2009)

Spinardi, G.: Up in the air: barriers to greener air traffic control and infrastructure lock-in in a complex socio-technical system. Energy Res. Soc. Sci. 6, 41-49 (2015)

TfL: Drivers of Demand for Travel in London: A review of Trends in Travel Demand and Their Causes. Transport for London, London (2014)

Urry, J.: The 'system' of automobility. Theory Cult. Soc. 21(4-5), 25-39 (2004)

Urry, J.: Governance, flows, and the end of the car system? Glob. Environ. Change 18, 343-349 (2008)

Vij, A., Gorripaty, S., Walker, J.L.: From trend spotting to trend'splaining: understanding modal preference shifts in the San Francisco Bay Area. Transp. Res. Part A Policy Pract. 95, 238-258 (2017)

Walker, W.E., Marchau, V.A.W.J., Swanson, D.: Addressing deep uncertainty using adaptive policies: introduction to section 2. Technol. Forecast. Soc. Change 77, 917-923 (2010)

Watson, M.: How theories of practice can inform transition to a decarbonised transport system. J. Transp. Geogr. 24, 488-496 (2012)

Whitehead, M.: The Leeds Trolley Vehicle System Order 201[], Report to the Secretary of State for Transport and the Secretary of State for Communities and Local Government, The Planning Inspectorate, TWA/13/APP/04 and NPCU/LBC/CAC/N4720 (2015)

Zmud, J., Ecola, L., Phelps, P., Feige, I.: The Future of Mobility: Scenarios for the United States in 2030. RAND Corporation, Washington. http://www.rand.org/pubs/research_reports/RR246.html (2013)

Greg Marsden is a Professor of Transport Governance at the Institute for Transport Studies, University of Leeds. He has researched issues surrounding the design and implementation of new policies for over 15 years covering a range of issues including energy and climate change. Current work examines how the smart mobility transition will change how we think about what, how and who governs the mobility system.

Noreen C. McDonald is Professor and Chair of the Department of City \& Regional Planning at the University of North Carolina at Chapel Hill. She has studied that links between transport infrastructure provision and public health and assessed the causes of large-scale changes in travel behavior. Her current work investigates how autonomous vehicle will impact vulnerable road users. 